\title{
Assessing social dominance in pairs of male rats by measuring weight gain
}

\section{KERMIT T. HOYENGA and THOMAS C. ROWE, Western Illinois University, Macomb, Ill. 61455}

It was found that pairs of male rats exhibit the same dominance hierarchy competing for food as evidenced in competition for water. There was, however, greater stability in the hierarchy competing measures of dominance examined in this study, per cent gain in weight and actual gain in weight, appear to be more reliable and perhaps more meaningful measures of dominance than time spent at food cup or judgments as to which rat is the dominant member of the pair.

The dominance hierarchy in the rat was studied as early as 1945 (Seward) when it was decided that rats do not establish a stable hierarchy The question, however, turned out to be far from settled; recent experiments have yielded conflicting results.

Baenninger (1966) found a reliable hierarchy on the basis of winners of "spontaneous encounters" using rotatedpair comparisons. Candland \& Bloomquist (1965), on the other hand, did not find a reliable hierarchy when the dominant $S$ was the S who was judged to have "possessed" the food cup longer than its competitor on a test trial. They used repeated measures of the same pair and hypothesized the nonstability to be due to the use of large numbers of Ss (10) in the home cages. It is also possible, however, that the results were due to this measure of dominance. Another method which has become somewhat standard is timing possession of the food cup. Using this measure, Becker \& Flaherty (1966) found the hierarchy to be unstable.

Schumsky \& Jones (1966), using females as well as males, found a stable dominance hierarchy not dependent on level of for food than competing for water. Both

deprivation or whether food or water was used. However, their method involves pretraining. The rats run down a straightalley runway for reward. This pretraining is followed by test trials to determine which $S$ will push the other back so he can reach his reward at the opposite end of the runway. This method of assessing dominance may be questioned as it involves competition away from goal and this is, in part, dependent upon strength of the running-to-goal response. The present study was an attempt to examine dominance with dominance measured as the relative amount of food or water obtained in competition with the other S.

\section{SUBJECTS AND APPARATUS}

Male Sprague-Dawleys $(\mathrm{N}=18)$ were placed in group cages of dimensions $9 \times 16$ in. at age 40 days, six Ss per cage. The two test cages were the same size as the colony cages but with their sides raised from 7 to $15 \mathrm{in.}$ In one cage, used for testing food competition, a food cup, 1.25 in. in diam, was kept filled with wet mash. It was placed in the center of the cage, the mouth flush with the floor. In the other test cage a single water bottle was attached to the side in the same position as the one used in the colony cages. Testing was begun at 72 days of age.

\section{PROCEDURE}

The Ss within each cage were randomly paired, and these original nine pairings were used throughout the 12 days of testing. The paired Ss competed for food 6 days and water 6 days, six pairs for food first and three pairs for water first. There was a 3-day period after the first 6 test days during which deprivation schedules were reversed. The Ss were always food- or water-deprived for $22-23 \mathrm{~h}$.

Testing under each condition was carried out for trial lengths of 2,4 , and $8 \mathrm{~min}$, presented in a counterbalanced order. Each

Table 1

Number of Times Dominant S Dominated (gained more weight) in the 108 Contests Trial Length

\begin{tabular}{lcccc} 
Competing for & $2 \mathrm{~min}$ & $4 \mathrm{~min}$ & $8 \mathrm{~min}$ & Totals \\
\hline Food & $18 \mathrm{p}<.001$ & $17 \mathrm{p}<.001$ & $17 \mathrm{p}<.001$ & $52 \mathrm{p}<.001$ \\
Water & $15 \mathrm{p}<.004$ & $15 \mathrm{p}<.004$ & $11 \mathrm{p}<.24$ & $41 \mathrm{p}<.001$ \\
Totals & $33 \mathrm{p}<.001$ & $32 \mathrm{p}<.001$ & $28 \mathrm{p}<.001$ & $93 \mathrm{p}<.001$ \\
\hline
\end{tabular}

$S$ was weighed before and after each test trial. Actual and percentage changes in weight were computed. Ss not on water deprivation had ad lib access to water, and vice versa for Ss not on food deprivation. On one test day Ss were timed for time spent at the food cup or at the water bottle.

$$
\text { RESULTS }
$$

In each pair the $S$ gaining the most weight on the majority of (12) trials was considered "dominant." Since each of the nine pairs competed 12 times, 6 for food and 6 for water, there were a total of 108 occasions to assess dominance. As can be seen in Table 1, only in the 18 contests for water lasting $8 \mathrm{~min}$ did the dominant $\mathrm{Ss}$ fail to win significantly more times than "submissive" Ss. The tabled probabilities associated with the observed frequencies were determined by the binomial sign test. The tetrachoric correlation coefficient between weight and dominance was +.5 , n.s. . The product moment correlation coefficient between time possessing food or water source and weight gain was $+.5(\mathrm{df}=16$, n.s. $)$. The product moment correlation coefficient between per cent gain in weight and actual gain in weight was $+.95(\mathrm{df}=16, \mathrm{p}=.005)$. DISCUSSION

The results indicate that male rats establish a very stable dominance hierarchy as measured by weight gain. This measure seems to have several advantages over other measures. (1) It is an easy measure to obtain, requiring no judgments as to which $S$ possesses incentive (Becker \& Flaherty, 1966). (2) It is not highly correlated with $S$ weight as Baenninger (1966) and Schumsky \& Jones (1966) reported. (3) It requires no pretraining of $S$ such as the procedure followed by Schumsky \& Jones (1966). Pretraining necessarily involves extensive handling of Ss prior to testing for dominance. Such handling may have an effect on dominance hierarchy (Becker \& Flaherty, 1966). (4) It is a measure expandable to situations where more than two Ss are tested simultaneously for dominance and over longer periods.

\section{REFERENCES}

BAENNINGER, $L$. The reliability of dominance orders in rats. Aaimal Behaviour, 1966, 14, 367-371.

BECKER, G, \& FLAHERTY, T. Effects of postweaning tactual stimulation on emotionality and social dominance in the rat. Psychological Reports, 1966, 19, 363-366.

CANDLAND, D., \& BLOOMQUIST, D. Interspecies comparisons of the reliability of dominance orders. Joumal of Comparative \& Physiological Psychology, 1965, 59, 135-137. SCHUMSKY, D., \& JONES, P. Reliable paired comparison dominance orders in rats. Psychological Record, 1966, 16, 473-478.

SEWARD, J. Aggressive beh avior in the rat: II. An attempt to establish a dominance hierarchy. Journal of Comparative Psychology, 1945, 38, 213-224. 